\title{
Combining insulins with oral antidiabetic agents: effect on hyperglycemic control, markers of cardiovascular risk and disease
}

\author{
Kjeld Hermansen \\ Lene Sundahl Mortensen \\ Marie-Louise Hermansen \\ Department of Endocrinology and \\ Metabolism C, Aarhus University \\ Hospital, DK-8000 Aarhus, Denmark
}

Correspondence: Kjeld Hermansen Department of Endocrinology and Metabolism C, Aarhus University Hospital, Tage-Hansens Gade 2, DK-8000 Aarhus C, Denmark

Tel +4589497651

Fax +4586193807

Email kjeld.hermansen@as.aaa.dk

\begin{abstract}
Patients with type 2 diabetes mellitus (T2DM) have an increased risk of cardiovascular disease (CVD). Unfortunately, several potential barriers exist for CVD risk management in diabetes, including the need for significant lifestyle changes, potential problems with hypoglycemia, weight gain, injection tolerability, treatment complexity with current diabetes therapies and other, unmodifiable factors. Improving glycemic control may impact CVD risk. Treatment of T2DM usually starts with lifestyle changes such as diet and exercise. When these become insufficient, pharmacotherapy is required. Various oral antidiabetic drugs (OADs) are available that reduce hyperglycemia. The first line of therapy is usually metformin, since it does not increase weight and seems to have a beneficial effect on CVD mortality and risk factors. As T2DM progresses, insulin treatment becomes necessary for the majority of patients. The last few years have seen the development of long-acting, rapid-acting, and premixed insulin analog formulations. The treat-to-target algorithms of recent studies combining OADs plus insulin analogs have demonstrated that patients can reach glycemic treatment targets with low risk of hypoglycemia, greater convenience, and - with some analogs - limited weight gain vs conventional insulins. These factors may possibly have a positive influence on CVD risk. Future studies will hopefully elucidate the benefits of this approach.
\end{abstract}

Keywords: diabetes mellitus, type 2 diabetes, cardiovascular disease, hyperglycemia, insulin, oral antidiabetic drugs

\section{Introduction}

Type 2 diabetes mellitus (T2DM), a progressive disease characterized by insulin resistance and eventual insulin deficiency, is caused by a gradual decrease of insulin secretion following loss of beta-cell function (Polonsky 1988). This pathology results in progressively increasing blood glucose levels. Typically, postprandial plasma glucose (PPG) becomes elevated first, with fasting glucose ultimately increasing as well (Coates 1994). Interventional studies have established chronic high blood glucose (assessed by $\mathrm{HbA1c}$ ) as a CVD risk factor (Stratton et al 2000; Davis et al 2001). That elevated PPG is an independent risk factor for CVD has further been implicated from epidemiological studies (DECODE 2001). Diabetes is also associated with other risk factors such as hypertension, adverse lipid profiles and obesity. Even after correcting for these risk factors, CVD rates are still higher in patients with diabetes than in non-diabetic subjects, implying that hyperglycemia per se may amplify the underlying risk of CVD.

This increased risk of CVD and related problems leads to a higher risk of mortality compared with the general population. Epidemiological research conducted by the Centers for Disease Control and Prevention (CDC) (CDC 2003) examined the impact of T2DM on cardiovascular events and mortality, reaching the following conclusions:

- CVD is the leading cause of death among patients with diabetes; 
- CVD death rates are 2-4 times higher in adults with diabetes than in controls;

- Risk for stroke is 2-4 times higher among patients with diabetes than in those without it.

The objective of this article is to provide an overview of CVD risk factors in diabetes with emphasis on the role of glycemic control, and to examine whether current therapies in T2DM have beneficial effects on markers of macrovascular disease. Using recent data from treat-to-target trials, the review will consider insulin plus oral antidiabetic drug (OAD) treatments and their effect on glycemic control and cardiovascular risk factors.

\section{Cardiovascular (CV) risk in diabetes}

Although mortality due to CVD is declining in non-diabetic populations, patients with T2DM are at a high risk of CV morbidity and mortality (Kannel and McGee 1979; Schernthaner 1996). Some studies have reported that almost $75 \%$ of patients with T2DM die of macrovascular events, such as acute myocardial infarction (MI) and stroke (Laakso 1995). In a mortality study of more than 3000 patients, 4-year survival was $92 \%$ for patients with diabetes duration $\leq 5$ years, and $84 \%$ if diabetes duration was $>5$ years (Bo et al 2006). Most deaths were due to CVD (36\% and $41 \%$ for diabetes duration $\leq 5$ years and $>5$ years, respectively) (Bo et al 2006). A 7-year Finnish study suggested that the $\mathrm{CV}$ event rate for patients with diabetes without prior MI was as high as the event rate in patients without diabetes with prior MI (Haffner et al 1998).

CVDs common in T2DM include coronary artery disease, stroke, peripheral vascular disease, cardiomyopathy and congestive heart failure. Several of these pathologies are usually present in a majority of patients; therefore most patients require multiple interventions (Kannel 2000). At the 2007 annual meeting of the American Diabetes Association, the authors of a 3.3 million populationbased study proposed that patients with T2DM should be treated with antiplatelet drugs, statins, ACE inhibitors, or angiotensin receptor blockers, because they carry the same CV risk as patients with a history of MI (Schramm et al 2007).

Although CVD accounts for a high proportion of deaths, patient awareness remains low (CDC 2003), and opportunities to intervene and modify the risks are missed. The high risk of morbidity and mortality in patients with diabetes indicates that it is vital to implement timely interventions in order to minimize CV complications (Stolar et al 2003).

\section{Factors contributing to increased CV risk in diabetes}

Patients with T2DM usually present various factors contributing to the risk of $\mathrm{CV}$ problems. These include hyperglycemia and fluctuation of blood glucose, central (visceral) obesity, hypertension, lipid abnormalities, hyperinsulinemia, and endothelial dysfunction (Stolar et al 2003).

The increased risk of CV morbidity and mortality associated with diabetes has led to the concept that hyperglycemia may be one of the risk factors for CVD (Haffner et al 2003). A prospective study of CVD in patients with T2DM reported that $\mathrm{CVD}$ episodes at 6.3 years were related to baseline HbA1c (Rius Riu et al 2003). A significant increase in the risk for $\mathrm{CV}$ events and mortality has been reported in patients with $\mathrm{HbA1c}>7 \%$ compared with those who had lower HbA1c values (Kuusisto et al 1994). The UK Prospective Diabetes Study (UKPDS) showed a more than 2-fold increase in incidence of MI over a range of $\mathrm{HbA} 1 \mathrm{c}$ values from $<6 \%$ to $\geq 10 \%$; each $1 \%$ reduction in $\mathrm{HbA} 1 \mathrm{c}$ was associated with a reduction in risk of $21 \%$ for any diabetes endpoint and death, and 14\% for MI (Stratton et al 2000) (Figure 1).

PPG control also plays a significant role in overall glycemic control and becomes even more important than fasting plasma glucose (FPG) when better control (eg, HbA1c level <8.4\%) is achieved (Monnier et al 2003). Excessive postprandial hyperglycemia may also be an important independent contributor to the risk of $\mathrm{CV}$ complications and mortality in T2DM (Massi-Benedetti and Federici 1999; Ceriello et al 2006). Interestingly, the deterioration of glucose homeostasis in the evolution of T2DM progresses from postprandial to fasting hyperglycemia (Monnier et al 2007). The Diabetes Intervention Study showed that PPG level can be used to predict the risk of MI (Hanefeld et al 1996). In a more recent, 5-year prospective study, PPG was an independent CVD risk factor in patients with T2DM, particularly women (Cavalot et al 2006).

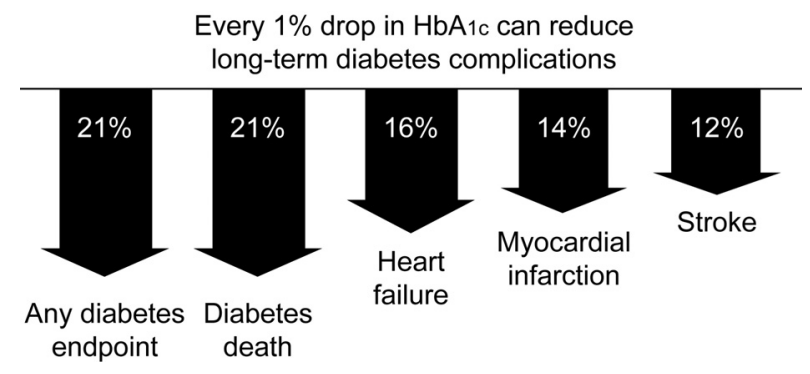

Figure I Improvement in glycemic control reduces risks of long-term complications (Stratton et al 2000). 
Thus, attaining glycemic control, and reducing CVD risk, may be difficult without adequate control of PPG levels.

Another major risk factor for developing T2DM is obesity. An estimated $80 \%$ of patients with T2DM are overweight and of that $37 \%$ are obese prior to diagnosis (Wolf and Colditz 1998). Epidemiological studies have demonstrated a clear association between obesity and CVD (Lemieux and Despres 1994), with visceral rather than peripheral fat being most harmful. A recent cross-sectional study of 44,042 patients with T2DM reported that $80 \%$ were overweight and $37 \%$ obese (Ridderstraale et al 2006). Such excessive weight is associated with insulin resistance, impaired glucose homeostasis, dyslipidemia, and hypertension - all risk factors associated with CVD.

Hypertension is also a major risk factor for such microvascular and macrovascular complications as retinopathy, nephropathy, stroke, and MI. It is estimated that the prevalence of hypertension in T2DM ranges from 20\% to $60 \%$ (ADA 2002), more than twice that seen in controls. In the Multiple Risk Factor Intervention Trial (MRFIT), mortality risk increased with increasing blood pressure, and the absolute level of risk in patients with diabetes was at least 3 times higher than that in controls (Stamler et al 1993). In another study of patients with T2DM, hypertension and $\mathrm{HbA} 1 \mathrm{c}$ at baseline were related to CVD episodes after 6 years (Rius Riu et al 2003). The UKPDS demonstrated that blood pressure control achieved with lifestyle modification and pharmacotherapy can result in risk reductions of $24 \%$ in diabetes-related endpoints, $32 \%$ in diabetes-related deaths, and 44\% in stroke (UKPDS 38 1998).

Another complication associated with diabetes is a chronic, low-level inflammatory state, possibly caused by oxidative stress or by glycosylation of proteins that activate macrophages. Elevated levels of C-reactive protein - a marker of subclinical inflammation - present in patients with T2DM, especially among older age groups (Kalofoutis et al 2006), have been identified as a predictor of first MI and CVD (Ridker et al 2000). In case of impaired metabolic state, postprandial hyperglycemia increases the magnitude and duration of systemic inflammatory responses, possibly promoting the development of T2DM and CVD (Kempf et al 2006). Elevated C-reactive protein levels have also been reported in patients with type 1 diabetes (T1DM) without macrovascular disease, suggesting that inflammation precedes atherosclerosis (Schalkwijk et al 1999).

Lipid abnormalities such as elevated levels of triglycerides (TG), small dense LDL cholesterol and decreased levels of HDL cholesterol have been consistently reported in diabetes, and these abnormalities dramatically increase the risk of macrovascular disease (Reaven 1995). In the Diabetes Control and Complications Trial (DCCT), treating T1DM subjects intensively for a mean of 6.5 years showed that high total cholesterol, high LDL cholesterol, high $\mathrm{HbA} 1 \mathrm{c}$ at baseline were associated with the development of CVD during the 17 years of follow-up (Nathan et al 2005). In a 7-year study of patients with T2DM, a previous history of MI, low HDL cholesterol, high LDL cholesterol, high TG, and high FPG was associated with a 2-fold increase in the risk of CVD morbidity and mortality (Lehto et al 1997). In T2DM, high postprandial TG responses have been associated with MI (Carstensen et al 2004).

\section{Barriers to effective blood glucose management in diabetes}

Before considering the treatment options for CVD risk in diabetes, it should be noted that there are several potential barriers to achieving good glycemic control. Lifestyle issues such as diet, exercise, and weight control are of great importance in managing T2DM, and represent vital opportunities for patients to influence their prognosis with regard to CV complications (O'Keefe et al 1999). Regular exercise, weight loss, and a special diet have been demonstrated to improve insulin sensitivity (Manson et al 1992; Wing et al 1995; Knopp et al 1997), which may be beneficial for the prognosis of T2DM, but many patients with T2DM have long-established behavioral patterns and find it very hard to modify their dietary and exercise habits.

The risk of hypoglycemia always exists when blood glucose-lowering therapies are used in patients with diabetes, and this is especially problematic with exogenous insulin therapy. The fear of hypoglycemic events can limit the glycemic control that patients will strive for, and their CV risk may consequently remain higher than necessary (Davies 2004).

As noted above, many patients with T2DM are overweight. Diabetes treatments can cause further, unwelcome weight gain (Korytkowski 2002). Even when weight gain is not at a clinically significant level, the mere prospect of gaining weight may jeopardize treatment adherence, preventing patients from achieving glycemic targets and indirectly increasing their risk of CVD.

Injection tolerability and the impact of therapy on lifestyle can also be barriers to diabetes treatment. Injecting insulin often becomes a necessity in T2DM, but for some patients, multiple daily injections may be a source of anxiety, discomfort, or pain (Hanas and Ludvigsson 1997). Patients may consequently reduce their adherence to therapy, resulting in suboptimal glycemic control. 
Some non-modifiable risk factors may also play a role in CVD risk in diabetes. Female gender appears to increase CVD risk in diabetes; women treated with insulin have an especially high mortality risk (Kronmal et al 2006). Different ethnic groups may have different $\mathrm{CV}$ risk factors, such as body weight, lipid profiles, and blood pressure (Davis et al 2001), and a genetic component demonstrated in twin studies may also influence CVD risk in T2DM (Medici et al 1999; Poulsen et al 1999). Finally, a higher cost of insulin analogs than that of human insulin may also represent a barrier for a number of patients. For others, the improved predictability, tolerability, and flexibility of analogs may make the added expense more acceptable. Better adherence and fewer complications may translate to cost benefits and fewer medical expenses in the long-term (Meece 2006). Although cost, treatment satisfaction and other issues may have an important role in the treatment of T2DM they will not be discussed in detail here since the scope of this review is restricted to the clinical aspects of combining insulin and OADs.

\section{Glucose-lowering therapy and $\mathrm{CV}$ risk markers}

The mechanisms by which improved glycemic control reduces $\mathrm{CV}$ risk are not completely understood, but probably relate to improvement of dyslipidemia, endothelial dysfunction, vasomotor dysfunction, and coagulation abnormalities, all of which are aggravated by hyperglycemia (Avena et al 1998; Meigs et al 2000; Mather et al 2001). The recognition that achieving specific glycemic goals can substantially reduce morbidity has made the effective treatment of hyperglycemia a top priority in T2DM.

Initially, such lifestyle changes as diet, exercise and weight loss are utilized in order to reduce the insulin requirements of patients with diabetes. Since T2DM is a progressive disease that causes deterioration over time, addition of medication is the rule, not the exception, if treatment goals are to be met (UKPDS 33 1998; Turner et al 1999; Nathan et al 2006). OADs can be taken as monotherapy or in combination, and are designed either to increase insulin secretion or increase tissue sensitivity (Turner et al 1996). Metformin and thiazolidinediones (TZD) are often used as first-line OADs in an attempt to utilize the insulin still available in patients' circulation. These OADs can lower blood glucose with a low risk of hypoglycemia, but require the availability of endogenous insulin in order to exert a blood glucose-lowering effect. When OADs do not enable patients to reach glycemic targets, sulphonylureas (SUs) are often added. SUs increase pancreatic insulin secretion as long as sufficient beta-cell function is preserved, but can precipitate hypoglycemia. Their efficacy is comparable to that of the various OADs in improvement of glycemic control, with $\mathrm{HbAlc}$ reductions of $1 \%$ to $2 \%$ usually achieved (Bailey 2003 ). With the exception of metformin, however, clear evidence is lacking for a reduction in macrovascular disease specifically associated with OADs (Macfarlane et al 2007).

With the number of oral treatment options currently available, it is important to consider the pathogenesis of T2DM and the risk factors for long-term $\mathrm{CV}$ consequences, vascular dysfunction, and inflammation when selecting treatment. The conditions associated with diabetes mean that many patients are prescribed multiple medications, so it is also important to be aware of potential interactions, or at least of the comorbidities remaining to be investigated.

A recent systematic review (Bolen et al 2007) concluded that newer, more expensive agents such as TZD, Alphaglucosidase inhibitors, and meglitinides have effects on glycemic control and CV risk factors (blood pressure, lipids, and body weight) that are similar or superior to those of older agents such as SUs and metformin. An important issue neglected in this review is the additive effect on glycemic control obtained by combining different groups of OADs, since in order for patients to achieve effective improvement and reach their goals for glycemic control, a combination of OAD therapies is often used (Stolar et al 2003). For many patients, OAD therapy alone becomes inadequate over time, and insulin is added to the treatment regimen (Ahmed and Goldstein 2006). Indeed, at 9 years after diagnosis, almost $80 \%$ of T2DM patients require insulin treatment (Turner et al 1999; Wright et al 2002). Before reviewing the clinical studies using insulin plus OADs, the individual agents currently used in diabetes treatment will be briefly discussed.

\section{Metformin}

Metformin suppresses hepatic glucose production and is thought to increase insulin sensitivity (Goldstein 2002). It has been used for decades, and has a long record of safety. Metformin is usually the first OAD used in obese patients because - unlike other agents, such as SUs - it does not lead to weight gain (Hermann et al 1994). In combination therapy, metformin also appears to limit the weight gain associated with the use of other agents, such as TZDs and SUs (Turner et al 1998; Hermansen and Mortensen 2007). Metformin appears to reduce $\mathrm{CV}$ events, although the mechanism is not well understood.

A meta-analysis of 41 randomized controlled trials (RCTs) of metformin involving more than 3000 patients 
with T2DM reported that metformin effectively lowered $\mathrm{HbA} 1 \mathrm{c}$ and modestly reduced total and LDL cholesterol, but had no significant effect on blood pressure, HDL cholesterol, or triglycerides (Wulffelle et al 2004). Indeed, in the ADOPT study, glyburide was associated with a lower risk of cardiovascular events than metformin and rosiglitazone (Kahn et al 2006) However, the majority of studies have reported beneficial CV effects with metformin. The UKPDS showed that the intensive use of metformin in obese patients achieved a reduction of $36 \%$ in all-cause mortality and 39\% in MI (Turner et al 1998). Weight stabilization, improved lipid profile, reduced triglycerides and LDL cholesterol, and increased HDL cholesterol (Buse et al 2004) have also been reported. Metformin has been shown to improve endothelial dysfunction - a factor closely linked to the development of atherosclerosis (Mather et al 2001). The Hyperinsulinemia the Outcome of its Metabolic Effects (HOME) double-blind trial, which assessed the metabolic and cardiovascular effects of metformin when added to insulin, reported a significant improvement of endothelial function largely unrelated to changes in glycemic control (De Jager et al 2005). For these reasons, metformin has been the most commonly used drug in combination with insulin.

There are few limitations for the use of metformin, the most common of which include intolerance to its gastrointestinal side effects and its contraindication in renal or hepatic insufficiency (Ahmed and Goldstein 2006).

\section{Thiazolidinediones}

Insulin sensitizers, TZDs have become very popular in recent years because they exhibit more potent effects on metabolic syndrome parameters associated with insulin resistance than other OADs (Goldstein 2002). Although the precise mechanism of action of TZDs is still under investigation, it appears to be mediated by effects in adipose tissue. TZDs have been shown to cause redistribution of fat with a reduction in visceral adiposity, a marker of insulin resistance (Kelly et al 1999).

The TZDs pioglitazone and rosiglitazone have shown similar effects on glycemic control in T2DM, but differential effects on dyslipidemia. A recent meta-analysis of randomized, controlled trials showed differing outcomes on lipid profiles (Chiquette et al 2004). Pioglitazone had a neutral or beneficial effect on lipids, whereas rosiglitazone appeared to have more complex effects, including an associated increase in both LDL and total cholesterol and a neutral effect on TGs. Both drugs increased levels of HDL cholesterol. Improvements in endothelial dysfunction with associated reduction in microalbuminuria have also been reported (Watanabe et al 2000) independently of reduction in glycemia and blood pressure (Bakris et al 2003). The effects of TZDs on blood pressure have not been consistent, but reduction of blood pressure has been reported (St. John Sutton et al 2002). TZDs also appear to decrease plasma C-reactive protein levels in patients with T2DM (Haffner et al 2002).

PROACTIVE, a large study in more than 5000 patients with T2DM and known CVD, assessed the effect of pioglitazone on CV mortality and morbidity (Dormandy et al 2005). In this high-risk study population, an aggressive dose titration of pioglitazone or placebo was used as 'add-on' therapy to current treatment regimes to ensure the best possible glycemic control. There was a nonsignificant reduction in the primary composite endpoint after a mean follow-up of 34 months, and an HbA1c reduction of $0.5 \%$ (HR 0.90 ; $\mathrm{p}=0.095)$; however, despite a significant reduction in the secondary composite endpoint of all-cause mortality, nonfatal MI and stroke were observed (HR 0.84; $\mathrm{p}=0.027$ ) (Dormandy et al 2005).

There are also side effects associated with TZD use, including fluid retention (which can lead to significant weight gain), dilutional anemia and fluid overload. TZDs are contraindicated in patients with heart failure (Higgs and Krentz 2004). Importantly, the use of TZDs with insulin has been associated with an increased risk of heart failure (Kermani and Garg 2003). TZDs are consequently contraindicated with insulin use in some countries. In addition, a recent meta-analysis of 42 trials showed that rosiglitazone slightly increased the risk of MI, and might also increase the risk of CV death (Nissen and Wolski 2007). This finding has instigated a heated discussion among opinion leaders, but no definitive conclusions on safety have been reached to date.

\section{Insulin secretagogues}

SUs were a first-line treatment before the introduction of metformin and TZDs; currently, however, they are often placed second after metformin, and sometimes even third after TZDs (Ahmed and Goldstein 2006). Unlike metformin, SUs have not shown any consistent protective role in the development of CVD; moreover, it has been proposed that patients treated with SUs are at an increased risk of macrovascular disease. For example, the UKPDS reported mixed results associated with the use of SUs. Although there was a trend towards a $16 \%$ reduction in fatal and non-fatal myocardial infarction (Stratton et al 2000), increased mortality was reported in patients treated with SUs plus metformin (Turner et al 1998); however, SU-treated patients were an average of 5 years older, 
were more hyperglycemic, and were followed for 5 years less than patients who were not treated with SUs.

The main side effects associated with the use of SUs include weight gain (up to several $\mathrm{kg}$ ) and hypoglycemia, the latter occurring more frequently with the longer-acting SUs (eg, glibenclamide, glyburide). SUs have not been shown to improve blood pressure, and do not appear to have a consistent effect on lipids (Bailey 2003).

\section{Alpha-glucosidase inhibitors}

Alpha-glucosidase inhibitors (AGIs) reduce the rate of digestion of polysaccharides in the proximal small intestine, primarily lowering postprandial glucose levels without causing hypoglycemia. They are less effective than metformin or SUs, reducing $\mathrm{HbA} 1 \mathrm{c}$ by $0.5 \%$ to $0.8 \%$ (Van de Laar et al 2005). Gastrointestinal side effects are common with AGI treatment, and have led to discontinuation in $25 \%$ to $45 \%$ of participants in clinical trials (Van de Laar et al 2005). Interestingly, a recent meta-analysis of 7 long-term studies of AGI treatment with acarbose in T2DM demonstrated a reduction in CV events (Hanefeld et al 2004); however, this meta-analysis has been criticized for a number of reasons such as publication bias, heterogeneity, detection bias, and confounding factors (Van de Laar and Lucassen 2004). A recent Cochrane systematic review and meta-analysis of 41 studies of AGI monotherapy in patients with T2DM of at least 12 weeks did not detect any effect on CV morbidity or mortality (Van de Laar et al 2005). A potential benefit of AGI on CVD therefore still needs to be proven.

\section{Insulin}

It has been shown that hyperglycemia contributes to an increased risk of microvascular complications (nephropathy, retinopathy, and neuropathy) (Harris 1998), and that lowering glucose levels protects against these complications (DCCT 1993; Turner et al 1998; UKPDS 33 1998). Controlling blood glucose with insulin has the potential to be the most effective blood glucose-lowering therapy. Insulin is consistently reported to reduce microvascular complications such as small vessel arterial disease, retinopathy, nephropathy, and neuropathy (DCCT 1993; UKPDS 33 1998). In the UKPDS, intensive blood glucose control resulted in a $16 \%$ reduction in the risk of $\mathrm{MI}$ and a $25 \%$ reduction in the risk of microvascular complications (Turner at al 1998); however, there have been conflicting views in the past as to whether insulin actually benefits CVD risk. Some observational studies have reported an association between high insulin levels and an increased risk of CVD (Janka at al 1987; Liu et al 1992), and it has been suggested that hyperinsulinemia predisposes patients to atherosclerosis and its complications (O’Keefe et al 1999).

The RCTs comparing intensive and conventional insulin treatment have more often focused on microvascular rather than macrovascular complications (Muis et al 2005). An exception was the Diabetes Mellitus Insulin Glucose Infusion in Acute Myocardial Infarction (DIGAMI) study, which assessed the impact of insulin infusion (followed by subcutaneous insulin injections) in patients with T2DM and acute MI (Malmberg et al 1995, 1997). Here, a reduction of $28 \%(\mathrm{p}<0.05)$ in relative mortality was reported after 3.4 years in the insulin infusion group compared with a conventional treatment group (Malmberg et al 1995, 1997). However, DIGAMI 2 did not support this finding, or the idea that insulin-based treatment lowers the number of nonfatal myocardial reinfarctions and strokes (Malmberg et al 2005). This disappointing outcome may in part be due to difficulties experienced with recruitment and reaching targets, and the subsequent premature recruitment stop in DIGAMI 2 (Malmberg et al 2005).

Although some studies report that insulin-treated patients with diabetes have a worse $\mathrm{CV}$ prognosis than patients not treated with insulin (Mak et al 1997), this may be seen as intrinsic to the disease process. Patients with more severe diabetes are more likely to be treated with insulin (O'Keefe et al 1999), and insulin users may have had chronically raised blood glucose in the past (in the 'pre-diabetic range'), with CVD symptoms emerging years later - perhaps around the same time as the need for insulin treatment arose. Atherosclerosis progresses over many years, and the process is likely to begin long before treatment intervention. Insulin users, therefore, are by definition likely to have accrued vascular damage by the time they initiate insulin treatment.

As noted above, most RCTs have not directly investigated the association between insulin use and risk of CV events. However, a number of studies suggest that reduced blood glucose achieved through intensive insulin treatment will ultimately have a beneficial effect on CV risk. For example, in the Diabetes Control and Complications Trial/Epidemiology of Diabetes Intervention and Complications (DCCT/EDIC) study in T1DM, it was shown that intensive treatment has long-term beneficial effects on the risk of CVD (Nathan et al 2005). During 17 years of follow-up, intensive treatment reduced the risk of any CVD events by $42 \%$, and the risk of nonfatal MI, stroke, or death from CVD by $57 \%$ (Nathan et al 2005). The intensive therapy during the DCCT/EDIC study 
resulted in decreased progression of intima-media thickness 6 years after the end of the trial (Nathan et al 2003). The long-term follow-up data suggest that previous intensive treatment of T1DM has an extended benefit well beyond the treatment period.

In the Steno study (Gaede et al 1999), T2DM patients with microalbuminuria were treated for a variety of CVD risk factors with multiple interventions, including insulin. Intensified intervention reduced the risk for a combined endpoint of $\mathrm{CV}$ mortality, nonfatal MI, nonfatal stroke, coronary intervention, revascularization to legs, and amputation by $50 \%$ (Gaede and Pedersen 2004). This study clearly showed that when an integrated cardiovascular risk factor management program is employed that includes conventional cardiovascular drugs as well as insulin, a positive effect on CV prognosis is likely to be achieved in patients with T2DM.

\section{Insulin with OADs and the treat-to-target concept}

The UKPDS was one of the first studies to prospectively investigate outcomes in insulin-plus-OAD-treated patients with T2DM, and it showed that the risk of complications can be considerably reduced when 'near-normal' glycemic control is achieved (Davidson 2005; UKPDS 33 1998). It demonstrated that early addition of insulin to oral therapy can safely keep $\mathrm{HbA} 1 \mathrm{c}$ close to $7.0 \%$ in the first 6 years after diagnosis (47\% of patients in the SU with insulin group vs. $35 \%$ in insulin only group). (Wright et al 2002); however, the UKPDS did not use the modern insulin products currently available.

Many patients remain poorly controlled with OADs, and insulin initiation is often delayed and insulin doses not adjusted aggressively enough. When OAD therapy becomes insufficient, there are several options for insulin initiation. Exogenous insulin administration often aims to mimic the physiological profile of endogenous insulin secretion as closely as possible to match insulin supply to physiological need, but traditional human insulin products do not match this profile precisely. Several types of insulin analogs have been developed by improving the pharmacokinetic profile of human insulin that follows subcutaneous absorption, in order to achieve a better balance between glycemic control and tolerability of treatment. Long-acting insulin analogs simulate the low level, basal insulin secretion seen overnight and between meals, whereas rapid-acting insulin analogs have a fast onset and short duration of action designed to mimic the normal endogenous prandial insulin response, thereby limiting mealtime glucose excursions. Premixed insulin analogs consist of a mixture of a rapid-acting insulin analog and a slower-acting protaminated form of the analog, providing both basal and prandial insulin in one injection.

In recent years, several studies have examined combination treatments with insulin analogs plus OADs using a treat-to-target (TTT) algorithm. Patients usually continued using OADs, while insulin analog was introduced and systematically titrated to a defined glucose target. These studies have shown that with aggressive insulin titration, $\mathrm{HbA} 1 \mathrm{c}$ can be reduced to a clinically highly beneficial level. A study by Riddle et al (2003) was the first trial to use a TTT algorithm in patients poorly controlled with OADs, to which the basal analog insulin glargine was added. Dosage was titrated weekly towards a target $\mathrm{FPG} \leq 5.6 \mathrm{mmol} / \mathrm{L}$, and in 6 months, patients achieved impressive reductions in $\mathrm{HbA} 1 \mathrm{c}$, with the majority $(\sim 60 \%)$ reaching the target of $\mathrm{HbA} 1 \mathrm{c} \leq 7.0 \%$.

Table 1 shows the results of trials comparing long-acting insulin analogs with NPH insulin in insulin-naïve patients with T2DM. Reductions in HbA1c are usually similar between regimens (up to $1.8 \%$ ), with large proportions of patients achieving targets of HbAlc $\leq 7 \%$. The lack of difference in glycemic control is unsurprising, of course, because of the use of a common glycemic target and titration algorithm; however, use of insulin analogs generally results in a significantly lower risk of hypoglycemia than use of NPH. When basal insulin analogs are initiated, they can achieve clinically meaningful reductions in blood glucose together with a low risk of hypoglycemia (Figure 2). Thus, a key barrier to insulin titration is lowered, implying that in the everyday clinical setting, patients are more likely to be able to reach guideline glycemic targets without being thwarted by hypoglycemia.

Furthermore, when insulin detemir has been used, patients have achieved significant improvements in glycemic control without the excessive weight gain usually associated with insulin use. Two recent studies of insulin detemir added to oral therapy showed $\mathrm{HbA} 1 \mathrm{c}$ to decrease by $1.5 \%$ to $1.8 \%$, with mean weight gain only half that seen with NPH insulin (Table 1) (Hermansen et al 2006; Philis-Tsimikas et al 2006). When patients use self-adjusted dosing algorithm, the HbAlc improvements are comparable to those of a physician-driven algorithm, and weight change can be minimal $(0.1 \mathrm{~kg})$ (Meneghini et al 2007). This weight advantage of detemir further appears to relate to body mass index (BMI): patients gain less weight with increasing BMI (Hermansen et al 2006). These results suggest that with some insulin analogs, it is possible to achieve a good glycemic control with less weight gain than that of comparator insulins. It remains to be established whether better weight control is directly 
Table I Trials of basal insulin analogues in insulin-naïve patients with type 2 diabetes

\begin{tabular}{|c|c|c|c|c|c|c|c|c|}
\hline \multirow[t]{2}{*}{ Author } & & \multicolumn{2}{|l|}{ HbAlc } & \multicolumn{2}{|l|}{ FPG } & \multirow[t]{2}{*}{ Hypoglycemia } & \multirow[t]{2}{*}{ Weight gain (kg) } & \multirow[t]{2}{*}{ Dose } \\
\hline & & Baseline & End & Baseline & End & & & \\
\hline \multirow[t]{2}{*}{ Hermansen 2006} & Detemir NPH & 8.6 & 6.8 & II.I & 6.9 & $\operatorname{RR} 0.53^{\mathrm{a}}$ & $1.2^{\mathrm{a}}$ & $\mathrm{BD}$ \\
\hline & & 8.5 & 6.6 & 10.8 & 6.6 & & 2.8 & $\mathrm{ttt}$ \\
\hline \multirow[t]{4}{*}{ Philis-Tsimikas 2006} & Detemir am or pm & 9.1 & 7.5 & 11.5 & 8.6 & RR 0.68 & 1.2 & OD \\
\hline & $\mathrm{NPH}$ & & & & & & & \\
\hline & & 8.9 & 7.4 & 10.8 & 7.2 & $\operatorname{RR} 0.47^{\mathrm{a}}$ & $0.7^{b}$ & $\mathrm{ttt}$ \\
\hline & & 9.2 & 7.4 & 11.5 & 7.8 & & 1.6 & \\
\hline \multirow[t]{2}{*}{ Yki-Jarvinen 2000} & Glargine NPH & 9.1 & 8.34 & & & $\sim 34 \%^{c}$ & 2.57 & OD \\
\hline & & 8.9 & 8.24 & & & $\sim 42 \%$ & 2.34 & \\
\hline \multirow[t]{2}{*}{ Massi-Benedetti 2003} & Glargine NPH & 9.0 & 8.5 & 13.0 & 9.6 & $35 \%$ & 2.01 & OD \\
\hline & & 8.9 & 8.5 & 13.1 & 9.8 & $41 \%$ & 1.88 & \\
\hline \multirow[t]{4}{*}{ Fritsche 2003} & Glargine am or pm & 9.1 & $7.8^{\mathrm{a}}$ & 12.1 & 7.0 & $74 \%$ & 3.9 & OD \\
\hline & $\mathrm{NPH}$ & & & & & & & \\
\hline & & 9.1 & $8.1^{b}$ & 12.0 & 6.8 & $68 \%$ & 3.7 & \\
\hline & & 9.1 & 8.3 & 12.2 & 6.9 & $75 \%$ & 2.9 & \\
\hline \multirow[t]{2}{*}{ Riddle 2003} & Glargine NPH & 8.61 & 6.96 & 11.0 & 6.5 & $13.9^{c}$ & 3.0 & OD \\
\hline & & 8.56 & 6.97 & 10.8 & 6.7 & $17.7 \mathrm{e} / \mathrm{pt} / \mathrm{yr}$ & 2.8 & $\mathrm{ttt}$ \\
\hline \multirow[t]{2}{*}{ Eliaschewitz 2006} & Glargine NPH & 9.03 & 7.65 & 11.2 & 6.4 & $52.8 \% c$ & Not reported & OD \\
\hline & & 9.21 & 7.78 & 10.8 & 6.6 & $62.8 \%$ & & $\mathrm{ttt}$ \\
\hline
\end{tabular}

Notes: Between-treatment comparison: ${ }^{\mathrm{a}} \mathrm{p}<0.00 \mathrm{I} ;{ }^{\mathrm{b}} \mathrm{p}<0.0 \mathrm{I} ;{ }^{\mathrm{c}} \mathrm{p}<0.05$.

Abbreviations: ttt, treat-to-target study; hypoglycemia RR, relative risk; \%, \% of patients experiencing hypos; e/pt/y, events per patient year.

beneficial to CVD risk; however, it may have a beneficial effect on treatment compliance.

Patients who require insulin can also be started on a premixed insulin analog, which allows easy intensification with additional injections of the same insulin. $\mathrm{HbA} 1 \mathrm{c}$ reductions can be of a greater magnitude with premixed insulin analogs than with basal analogs (Table 2), largely because PPG can be better controlled with premixed human insulins than with basal insulin alone. For example, in a 6-month TTT study of insulin initiation, HbA1c was significantly better and a greater proportion of patients reached the target $\mathrm{HbA} 1 \mathrm{c}<7.0 \%$ with premixed insulin aspart than with the basal analog insulin glargine ( $66 \%$ vs. $40 \%$, respectively) (Raskin et al 2005). A study by Garber et al (2006) employed an aggressive titration algorithm to reach the target FPG of 4.5-6.1 mmol/L with premixed insulin aspart. The HbA1c target of $<7.0 \%$ was achieved by $41 \%$ of patients with oncedaily, by $70 \%$ with twice-daily, and by $77 \%$ of patients with three times-daily premixed insulin aspart. Figure 3 shows that premixed insulins can achieve greater reductions in $\mathrm{HbA} 1 \mathrm{c}$ than basal insulins, but with a slightly higher risk of hypoglycemia. Premixed insulin analogs may therefore represent an effective treatment option in terms of achieving glycemic control, although weight gain and the risk of hypoglycemia may be more of an issue than when basal insulin alone is added to OADs. A recently published study by the 4-T Study Group (Holman et al 2007) compared the use of premixed insulin aspart twice-daily, prandial insulin aspart three-times daily, and basal insulin detemir once daily (twice if required) in patients with type 2 diabetes inadequately controlled with metformin and SUs. After 1 year, HbA1c levels were similar in the premixed insulin group (7.3\%) and the pradial group (7.2\%), but higher in the basal group (7.6\%). However, the respective mean numbers of hypoglycemic events per patient per year were 5.7, 12.0, and 2.3, and weight gains were $4.7 \mathrm{~kg}$, $5.7 \mathrm{~kg}$, and $1.9 \mathrm{~kg}$, suggesting that premixed insulin aspart and prandial insulin aspart reduced $\mathrm{HbA} 1 \mathrm{c}$ levels more than basal insulin detemir but were associated with greater risks of hypoglycemia and weight gain (Holman et al 2007).

There is currently no consensus as to which option represents the best way to initiate and intensify insulin treatment. Patients are often started on a once-daily basal insulin analog at bedtime, which improves FPG with a relatively low risk of nocturnal hypoglycemia. Using this strategy, PPG excursions may be controlled by a combination of OADs and the recovered beta-cell secretory capacity that basal insulin supplementation may afford. There does seem to be a limit to the $\mathrm{HbAlc}$ reduction that can be achieved when 


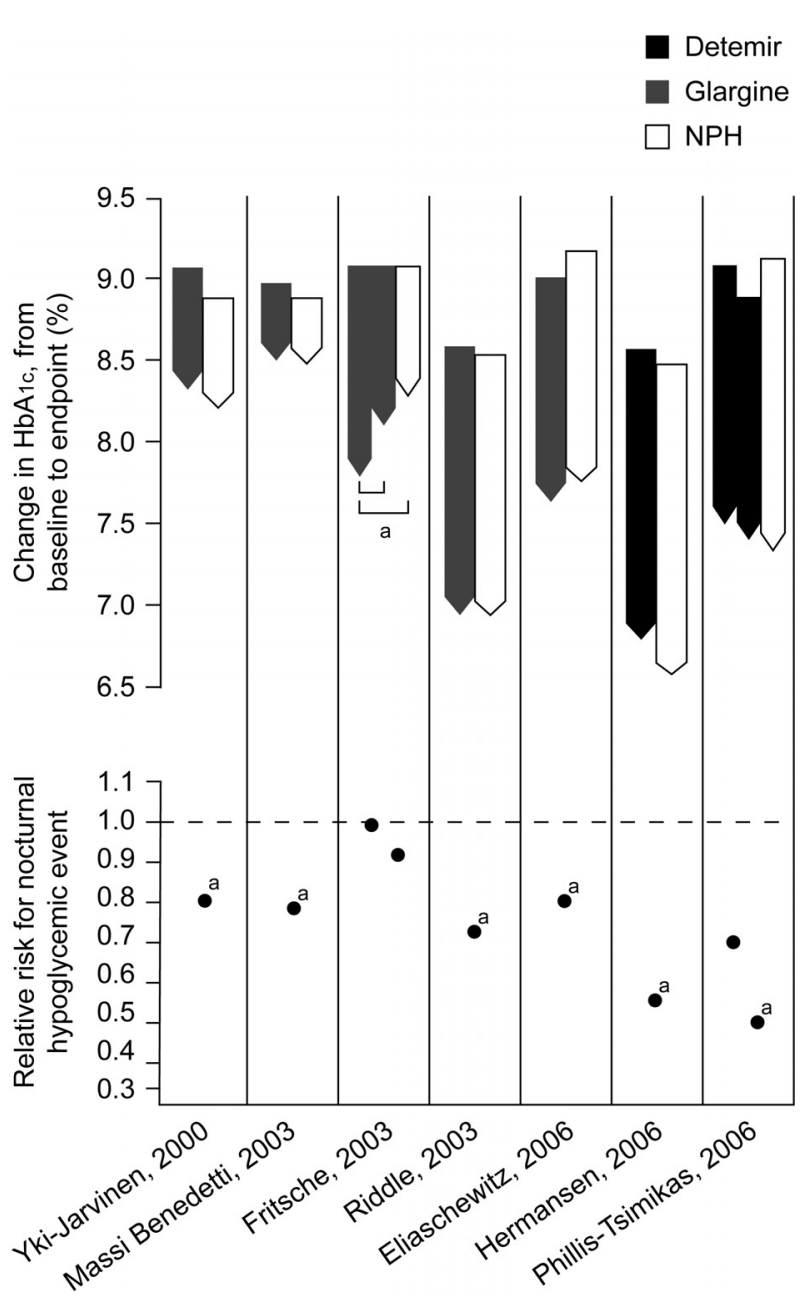

Figure 2 Mean change in $\mathrm{HbAlc}$ (baseline to endpoint) and relative risk for all-day hypoglycemia in comparative trials of basal analogs vs. NPH insulin plus OADs in T2DM. Note: definitions of hypoglycemia vary by study; the glargine 'relative percentages' have been derived from the study publications and are not comparable to the relative risk data presented for detemir. ${ }^{\mathrm{a}} \mathrm{p}<0.05$ for between treatment difference in change in $\mathrm{HbAlc}$ between baseline and end of trial, or in risk of hypoglycaemia (De Vries et al 2007 [in press]). (C) Reproduced with permission.

basal insulin alone is added to OADs, as evidenced by the observation that studies involving cohorts with higher baseline levels of $\mathrm{HbA} 1 \mathrm{c}$ tend to achieve mean absolute $\mathrm{HbA} 1 \mathrm{c}$ levels at endpoint that, while improved, remain above target (De Vries et al 2007). There is also evidence that the effect of a once-daily basal insulin is more likely to wane across 24 hours when baseline control is poorer, and that splitting the dose will merely escalate the dose without a corresponding gain in control (DeVries et al 2007). These observations likely reflect in part an increasing failure to limit postprandial glycemic control with progressing T2DM.

Furthermore, as $\mathrm{HbA} 1 \mathrm{c}$ decreases, so PPG contributes an increasing proportion of the residual hyperglycemia (Monnier et al 2003). It follows that in order to achieve $\mathrm{HbA1c}$ treatment goals, PPG control must be targeted as well, particularly in more advanced disease. When OADs no longer adequately control PPG excursions, prandial insulin can be added at mealtimes, one meal at a time, to a simple basal insulin regimen. Alternatively, premixed insulin formulations can be used for insulin initiation and intensification of treatment, with the advantage of fewer daily injections but more limited flexibility. Using this approach, patients can use the same insulin in the same device, just increasing the number of daily injections (Garber et al 2006). Ongoing studies will likely discern patient preferences and the optimal treatment strategies for defined patient types.

\section{Conclusions}

It is well established that patients with diabetes are at a high risk of CVD. Blood glucose control appears to be an important factor in reducing the CVD risk and potential CV mortality in diabetes patients. Most studies examining insulin plus OADs have focused on insulin, with OADs usually grouped together - although most trials have used metformin as either the only OAD or in combination with other OADs (eg, Riddle et al 2003; Hermansen et al 2006; Philis-Tsimikas et al 2006). The combination of insulin plus OADs has been associated with improvements in $\mathrm{CV}$ risk markers in early outcome studies, but studies examining the interactions of various antidiabetic treatments would also be helpful.

The TTT studies have shown that insulin analogs plus OAD can help patients to achieve excellent glycemic control. Adding a basal insulin analog to OAD therapy improves HbA1c by $1.5 \%$ to $1.8 \%$, with a low risk of hypoglycemic events. Premixed insulin analogs have shown greater $\mathrm{HbA} 1 \mathrm{c}$ reductions, but considerable weight gain; however, the longacting insulin analog detemir appears to limit the weight gain usually present with insulin use (Hermansen et al 2006; Philis-Tsimikas et al 2006). This effect may help improve adherence to treatment.

There are different views as to which approach is the best option for initiation or intensification of insulin, when the need arises. With a basal insulin analog injection as a start, rapid-acting insulin can be added at mealtimes. On the other hand, premixed insulin analogs contain both basal and prandial insulin in one injection. The clinician and patient must decide which of these options they find more acceptable. Observational studies have also shown that patients can easily manage self-monitoring and self-titration of insulin analogs (Davies et al 2005; Meneghini et al 2007). Insulin analogs appear to be a better option than conventional insulins for achieving the balance between glycemic control and risk of hypoglycemia. Data concerning the impact of different 
Table 2 Trials of premixed insulin analogues in patients with type 2 diabetes

\begin{tabular}{|c|c|c|c|c|c|c|c|c|}
\hline \multirow[t]{2}{*}{ Author } & & \multicolumn{2}{|l|}{ HbAlc } & \multicolumn{2}{|l|}{ FPG } & \multirow[t]{2}{*}{ Hypoglycemia } & \multirow[t]{2}{*}{ Weight gain } & \multirow[t]{2}{*}{ Dose } \\
\hline & & Baseline & End & Baseline & End & & & \\
\hline \multicolumn{9}{|c|}{ Insulin-naïve patients } \\
\hline \multirow[t]{2}{*}{ Malone 2004} & $\operatorname{Mix} 25$ & 8.7 & $7.4^{\mathrm{b}}$ & 8.5 & $7.7^{c}$ & $0.68^{\mathrm{c}} \mathrm{mi}$ & $2.3^{b}$ & BID \\
\hline & Glargine & 8.7 & 7.8 & 8.5 & 6.9 & $0.39 \mathrm{e} / \mathrm{pt} / 30$ days & 1.6 & OD \\
\hline \multirow[t]{2}{*}{ Kilo 2003} & BIAsp 30 & 9.5 & $8.2^{\mathrm{e}}$ & 13.4 & $9.2^{\mathrm{e}}$ & $43 \%$ & 0.7 & OD \\
\hline & $\mathrm{BHI}$ & 9.3 & $8.2^{\mathrm{e}}$ & 12.6 & $9.1^{\mathrm{e}}$ & $32 \%$ & 1.0 & OD \\
\hline \multirow[t]{2}{*}{ Raskin 2005} & BIAsp 30 & 9.7 & $6.9^{\mathrm{b}}$ & 14.0 & 7.1 & $3.4^{c}$ & $5.4^{b}$ & BID \\
\hline & Glargine & 9.8 & 7.4 & 13.5 & 6.5 & $0.7 \mathrm{e} / \mathrm{pt} / \mathrm{yr}$ & 3.5 & OD ttt \\
\hline \multirow[t]{2}{*}{ Kann 2006} & BIAsp 30 & 9.21 & $7.5^{\mathrm{a}}$ & 11.0 & 8.6 & $20.3 \%^{c}$ & 0.7 & BID \\
\hline & Glargine & 8.9 & 7.9 & 11.5 & 9.1 & $9 \% \mathrm{mi}$ & 1.5 & OD \\
\hline \multicolumn{9}{|c|}{ Patients previously treated with insulin } \\
\hline \multirow[t]{2}{*}{ Roach 1999} & $\operatorname{Mix} 25$ & & 7.8 & & & $42 \%$ & & BID \\
\hline & $\mathrm{BHI} 30$ & & 8.1 & & & $35 \%$ & & BID \\
\hline \multirow[t]{2}{*}{ Roach 1999} & Mix 25 & & 7.7 & & 8.9 & $40 \%$ & none & BID \\
\hline & $\mathrm{BHI} 30$ & & 7.7 & & 9.0 & $37 \%$ & & BID \\
\hline \multirow[t]{2}{*}{ Malone 2005} & Mix 25 & 8.5 & $7.5^{\mathrm{a}}$ & 8.4 & $7.9^{b}$ & 0.61 & $0.8^{\mathrm{a}}$ & BID \\
\hline & Glargine & 8.5 & 8.1 & 8.4 & 7.4 & $0.44 \mathrm{e} / \mathrm{pt} / 30$ days & 0.1 & OD \\
\hline \multirow[t]{2}{*}{ Boehm 2002 } & BIAsp 30 & $8.4 / 8.1$ & 8.1 & & 8.9 & $20 \mathrm{mj} / 362 \mathrm{mi}$ & & BID \\
\hline & $\mathrm{BHI} 30$ & $8.4 / 8.2$ & 8.2 & & 8.2 & $42 \mathrm{mj} / 36 \mathrm{Imi}$ & & BID \\
\hline \multirow[t]{2}{*}{ Liebl 2006} & BIAsp 30 & 8.4 & $7.2^{\mathrm{b}}$ & 11 & 8.1 & $28 \%$ & 2.2 & BID \\
\hline & $\begin{array}{l}\text { Detemir + } \\
\text { aspart }\end{array}$ & 8.2 & 7.0 & 11.2 & 8.2 & $31 \% \mathrm{mi}$ & 2.2 & OD \\
\hline \multirow[t]{3}{*}{ Garber 2006} & BIAsp 30 & 8.6 & 7.2 & 9.2 & 6.4 & 15.4 & $\sim 0.5$ & OD, \\
\hline & & & & & & 22.4 & & BID, \\
\hline & & & & & & $12.0 \mathrm{e} / \mathrm{pt} / \mathrm{yr}$ & & TID ttt \\
\hline
\end{tabular}

Notes: Between-treatment comparison: ${ }^{\mathrm{a}} \mathrm{p}<0.00 \mathrm{I} ;{ }^{\mathrm{b}} \mathrm{p}<0.0 \mathrm{I} ;{ }^{\mathrm{c}} \mathrm{p}<0.05$; Includes type I and 2 diabetes patients; ${ }^{\mathrm{e}} \mathrm{Calculated}$ value.

Abbreviations: ttt, treat-to-target study; hypoglycemia \%, \% of patients experiencing hypos; e/pt/y, events per patient year; mj, major; mi, minor.

insulin plus OAD regimens on CVD markers other than hyperglycemia are currently lacking, yet have the potential to guide treatment choices.

The role of OAD and of insulin-OAD combination regimens may change in the future as a result of the development of newer therapies. For example, glucagon-like peptide 1 (GLP-1) analogs, GLP-1 agonists and dipeptidyl peptidase IV (DPP-4) inhibitors represent very promising treatment options for patients with T2DM. GLP-1 secretion may be impaired in T2DM, and GLP-1 analogs and agonists and DPP-4 inhibitors that increase endogenous GLP-1 production have the advantage that their effect on insulin secretion depends on plasma glucose concentration. The first studies of GLP-1 analogs show encouraging improvements in glycemic control without the risk of hypoglycemia and with a dosedependent reduction in weight, a combination promising a potential CVD benefit (DeFronzo et al 2005; Vilsbøll et al
2006). It should be noted that despite its HbAlc- lowering effect, the DPP-4 inhibitor sitagliptin increases the risk of hypoglycemia when combined with SUs (Hermansen et al 2007). Although it remains to be determined whether these agents are likely to be used with insulin, an agent controlling glucose levels while decreasing weight gives rise to hope for beneficial treatment possibilities. Large, long-term comparative studies of major clinical endpoints, such as CVD, MI, and $\mathrm{CV}$ mortality, are needed to determine the comparative effects of OADs

In summary, it seems sensible to establish glycemic control in patients with T2DM by utilizing such lifestyle changes as diet intervention and exercise; however, current studies have shown that excellent glycemic control will ultimately require insulin treatment, at least in the more advanced stages of T2DM, and that this can be achieved with insulin plus OAD with a TTT approach. Patients and clinicians need to gain more confidence 
Mix 25

Glargine

BIAsp 30

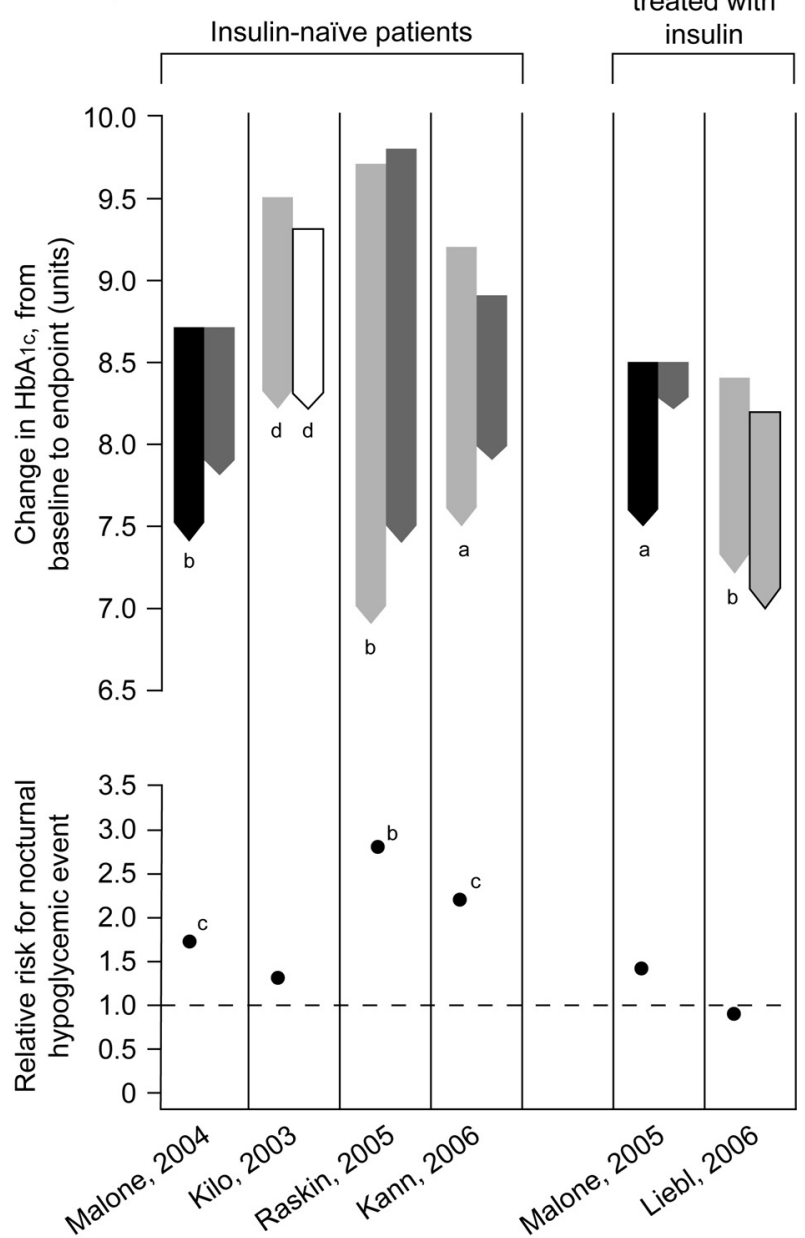

Figure 3 Mean change in $\mathrm{HbAlc}$ (baseline to endpoint) and relative risk for all-day hypoglycemia in comparative trials of premixed analogs plus OADs in T2DM. Betweentreatment comparison: ${ }^{\mathrm{a}} \mathrm{p}<0.00 \mathrm{I} ;{ }^{\mathrm{b}} \mathrm{p}<0.0 \mathrm{I} ;{ }^{\mathrm{c}} \mathrm{p}<0.05$. ${ }^{\mathrm{d}}$ Calculated value.

in initiating and titrating insulin, as this approach can lead to a better prognosis in terms of diabetes complications, including a reduced risk of CVD. A comprehensive approach for preventing and/or ameliorating the $\mathrm{CV}$ complications of diabetes would also require the use of lipid-lowering medication, control of blood pressure, and anticoagulation medication.

\section{References}

Ahmed I, Goldstein BJ. 2006. Cardiovascular risk in the spectrum of type 2 diabetes mellitus. Mt Sinai J Med, 73:759-68.

American Diabetes Association. 2002. Treatment of hypertension in adults with diabetes. Diabetes Care, 25:199-201.

Avena R, Mitchell ME, Nylen ES, et al. 1998. Insulin action enhancement normalizes brachial artery vasoactivity in patients with peripheral vascular disease and occult diabetes. J Vast Surg, 28:1024-31.

Bailey CJ, Day C. 2003. Antidiabetic drugs. Br J Cardiol, 10:128-36.

Bakris G, Viberti G, Weston WM, et al. 2003. Rosiglitazone reduces urinary albumin excretion in type II diabetes. J Hum Hypertens, 17:5-6.
Bo S, Ciccone G, Gancia R, et al. 2006. Mortality within the first 10 years of the disease in type 2 diabetic patients. Nutr Metab Cardiovasc Dis, 16:8-12.

Boehm BO, Home PD, Behrend C, et al. 2002. Premixed insulin aspart 30 vs. premixed human insulin 30/70 twice daily: a randomized trial in Type 1 and Type 2 diabetic patients. Diabet Med, 19:393-9.

Bolen S, Feldman L, Vassy J, et al. 2007. Systematic review: comparative effectiveness and safety of oral medications for type 2 diabetes mellitus. Ann Intern Med [in press].

Buse JB, Tan MH, Prince MJ, et al. 2004. The effects of oral antihyperglycemic medications on serum lipid profiles in patients with type 2 diabetes. Diabetes Obes Metab, 6:133-56.

Carstensen M, Thomsen C, Gotzsche O, et al. 2004. Differential postprandial lipoprotein responses in type 2 diabetic men with and without clinical evidence of a former myocardial infarction. Rev Diabet Stud, 4:175-84.

Cavalot F, Petrelli A, Traversa M, et al. 2006. Postprandial blood glucose is a stronger predictor of cardiovascular events than fasting blood glucose in type 2 diabetes mellitus, particularly in women: lessons from the San Luigi Gonzaga Diabetes Study. J Clin Endocrinol Metab, 91:813-9.

Centers for Disease Control and Prevention. 2003. National Diabetes Fact Sheet: National Estimates and General Information on Diabetes in the United States. Atlanta: US Department of Health and Human Services, Centers for Disease Control and Prevention.

Ceriello A, Davidson J, Hanefeld M, et al. 2006. Postprandial hyperglycemia and cardiovascular complications of diabetes: an update. Nutr Metab Cardiovasc Dis, 16:453-6.

Chiquette E, Ramirez G, DeFronzo R. 2004. A meta-analysis comparing the effect of thiazolidinediones on cardiovascular risk factors. Arch Intern Med, 164:2097-104.

Coates VE. 1994. Monitoring diabetic control. J Clin Nurs, 3:263-9.

Davidson MB. 2005. Starting insulin therapy in type 2 diabetic patients: does it really matter how? Diabetes Care, 28:494-5.

Davies M. 2004. The reality of glycemic control in insulin treated diabetes: defining the clinical challenges. Int J Obes, 28(Suppl 2):S14-22.

Davies M, Storms F, Shutler S, et al. 2005. Improvement of glycemic control in subjects with poorly controlled type 2 diabetes: comparison of two treatment algorithms using insulin glargine. Diabetes Care, 28:1282-8.

Davis TM, Cull CA, Holman RR; UK Prospective Diabetes Study (UKPDS) Group. 2001. Relationship between ethnicity and glycemic control, lipid profiles, and blood pressure during the first 9 years of type 2 diabetes: UK Prospective Diabetes Study (UKPDS 55). Diabetes Care, 24:1167-74.

De Jager J, Kooy A, Lehert PH, et al. 2005. Effects of short-term treatment with metformin on markers of endothelial function and inflammatory activity in type 2 diabetes mellitus: a randomized, placebo-controlled trial. J Intern Med, 257:100-9.

DECODE Study Group, for the European Diabetes Epidemiology Group. 2001. Glucose tolerance and cardiovascular mortality: comparison of fasting and 2-hour diagnostic criteria. Arch Intern Med, 161:397-405.

DeFronzo RA, Ratner RE, Han J, et al. 2005. Effects of exenatide (exendin4) on glycemic control and weight over 30 weeks in metformin-treated patients with type 2 diabetes. Diabetes Care, 28:1092-100.

DeVries JH, Nattrass M, Pieber TR. 2007. Refining basal insulin therapy: what have we learned in the age of analogues? Diabetes Metab Res Rev, 23:441-54.

Diabetes Control and Complications Trial Research Group. 1993. The effect of intensive treatment of diabetes on the development and progression of long-term complications in insulin-dependent diabetes mellitus. N Engl J Med, 329:977-86.

Dormandy JA, Charbonnel B, Eckland DJA, et al. 2005. Secondary prevention of macrovascular events in patients with type 2 diabetes in the PROactive Study (PROspective pioglitAzone Clinical Trial In macroVascular Events): a randomised controlled trial. Lancet, 366:1279-89. 
Eliaschewitz FG, Calvo C, Valbuena H, et al; HOE 901/4013 LA Study Group. 2006. Therapy in type 2 diabetes: insulin glargine vs. NPH insulin both in combination with glimepiride. Arch Med Res, 37:495-501.

Fritsche A, Schweitzer MA, Haring HU 4001 Study Group. 2003. Glimepiride combined with morning insulin glargine, bedtime neutral protamine Hagedorn insulin, or bedtime insulin glargine in patients with type 2 diabetes. A randomized, controlled trial. Ann Intern Med, 138:952-9.

Gaede P, Vedel P, Parving HH, et al. 1999. Intensified multifactorial intervention in patients with type 2 diabetes mellitus and microalbuminuria: the Steno type 2 randomised study. Lancet, 353:617-22.

Gaede P, Pedersen O. 2004. Intensive integrated therapy of type 2 diabetes: implications for long-term prognosis. Diabetes, 53:S39-47.

Garber AJ, Wahlen J, Wahl T, et al. 2006. Attainment of glycemic goals in type 2 diabetes with once-, twice-, or thrice-daily dosing with biphasic insulin aspart 70/30 (The 1-2-3 study). Diabetes Obes Metab, 8:58-66.

Goldstein BJ. 2002. Insulin resistance as the core defect in type 2 diabetes mellitus. Am J Cardiol, 90:3-10.

Haffner JS, Cassells H. 2003. Hyperglycemia as a cardiovascular risk factor. Am J Med, 115:S6-11.

Haffner SM, Lehto S, Ronnemaa T, et al. 1998. Mortality from coronary heart disease in subjects with type 2 diabetes and in nondiabetic subjects with and without prior myocardial infarction. $N$ Engl J Med, 339:229-34.

Haffner SM, Greenberg AS, Weston WM, et al. 2002. Effect of rosiglitazone on nontraditional markers of cardiovascular disease in patients with type 2 diabetes mellitus. Circulation, 106:679-84.

Hanas R, Ludvigsson J. 1997. Experience of pain from insulin injections and needle-phobia in young patients with IDDM. Pract Diab Int, 14:95-9.

Hanefeld M, Cagatay M, Petrowitsch T, et al. 2004. Acarbose reduces the risk for myocardial infarction in type 2 diabetic patients: meta-analysis of seven long-term studies. Eur Heart J, 25:10-6.

Hanefeld M, Fischer S, Julius U, et al. 1996. Risk factors for myocardial infarction and death in newly detected NIDDM: the Diabetes Intervention Study, 11-year follow-up. Diabetologia, 39:1577-83.

Harris MI. 1998. Diabetes in America: epidemiology and scope of the problem. Diabetes Care, 21:C11-4.

Hermann LS, Schersten B, Bitzen PO, et al. 1994. Therapeutic comparison of metformin and sulfonylurea, alone and in various combinations. A double-blind controlled study. Diabetes Care, 17:1100-9.

Hermansen K, Davies M, Derezinski T, et al. 2006. A 26-week, randomized, parallel, treat-to-target trial comparing insulin detemir with NPH insulin as add-on therapy to oral glucose-lowering drugs in insulin-naive people with type 2 diabetes. Diabetes Care, 29:1269-74.

Hermansen K, Mortensen LS. 2007. A review of bodyweight changes associated with antihyperglycemic agents in type 2 diabetes. Drug Safety, 30:1127-42.

Hermansen K, Kipnes M, Luo E, et al. 2007. Sitagliptin Study 035 Group. Efficacy and safety of the dipeptidyl peptidase-4 inhibitor, sitagliptin, in patients with type 2 diabetes mellitus inadequately controlled on glimepiride alone or on glimepiride and metformin. Diabetes Obes Metab, [in press].

Higgs ER, Krentz AJ. 2004. ABCD position statement on glitazones. Pract Diabetes Int, 21:293-5.

Holman RR, Thorne KI, Farmer AJ, Davies MJ, Keenan JF, Paul S, Levy JC. 4-T Study Group. Addition of biphasic, prandial, or basal insulin to oral therapy in type 2 diabetes. $N$ Engl J Med, 2007 Oct 25; 357(17):1716-30. Epub 2007 Sep 2.

Janka HU, Ziegler AG, Standl E, et al. 1987. Daily insulin dose as a predictor of macrovascular disease in insulin treated non-insulin dependent diabetics. Diabetes Metab, 13:359-64.

Kalofoutis C, Piperi C, Zisaki A, et al. 2006. Differences in expression of cardiovascular risk factors among type 2 diabetes mellitus patients of different age. Ann N Y Acad Sci, 1084:166-77.
Kann PH, Wascher T, Zackova V, et al. 2006. Starting insulin therapy in type 2 diabetes: twice-daily biphasic insulin aspart 30 plus metformin versus once-daily insulin glargine plus glimepiride. Exp Clin Endocrinol Diabetes, 114:527-32.

Kannel WB. 2000. The Framingham Study: its 50-year legacy and future promise. $J$ Atheroscler Thromb, 6:60-6.

Kannel WB, McGee DL. 1979. Diabetes and cardiovascular disease. The Framingham study. JAMA, 241:2035-8.

Kelly IE, Han TS, Walsh K, et al. 1999. Effects of a thiazolidinedione compound on body fat and fat distribution of patients with type 2 diabetes. Diabetes Care, 22:288-93.

Kempf K, Rose B, Herder C, et al. 2006. Inflammation in metabolic syndrome and type 2 diabetes: Impact of dietary glucose. Ann N Y Acad Sci, 1084:30-48.

Kermani A, Garg A. 2003. Thiazolidinedione-associated congestive heart failure and pulmonary edema. Mayo Clin Proc, 78:1088-91.

Kilo C, Mezitis N, Jain R, et al. 2003. Starting patients with type 2 diabetes on insulin therapy using once-daily injections of biphasic insulin aspart $70 / 30$, biphasic human insulin 70/30, or NPH insulin in combination with metformin. J Diabetes Complications, 17:307-13.

Knopp RH, Walden CE, Retzlaff BM, et al. 1997. Long-term cholesterollowering effects of 4 fat-restricted diets in hypercholesterolemic and combined hyperlipidemic men. The Dietary Alternatives Study. JAMA, 278:1509-15.

Korytkowski M. 2002. When oral agents fail: practical barriers to starting insulin. Int J Obes Relat Metab Disord, 26:S18-24

Kronmal RA, Barzilay J, Smith NL, et al. 2006. Mortality in pharmacologically treated older adults with diabetes: the Cardiovascular Health Study, 1989-2001. PLoS Med, 3:e400.

Kuusisto J, Mykkanen L, Pyorala K, et al. 1994. NIDDM and its metabolic control predict coronary heart disease in elderly subjects. Diabetes, 43:960-7.

Laakso M. 1995. Epidemiology of diabetic dyslipidemia. Diabetes Rev, 3:408-22.

Lehto S, Ronnemaa T, Haffner SM, et al. 1997. Dyslipidemia and hyperglycemia predict coronary heart disease events in middle-aged patients with NIDDM. Diabetes, 46:1354-9.

Lemieux S, Despres JP. 1994. Metabolic complications of visceral obesity: Contribution to the aetiology of type 2 diabetes and implications for prevention and treatment. Diabetes Metab, 20:375-93.

Liebl A, Prager R, Binz K, et al; on behalf of the PREFER study group. 2006. The PREFER Study: both biphasic insulin aspart 30 (BIAsp 30) twice-daily and basal-bolus using insulin detemir (IDet) and insulin aspart (IAsp) enabled patients with type 2 diabetes to achieve Alc target $<7.0 \%$. Diabetologia, 49(Suppl 1):610.

Liu QZ, Knowler WC, Nelson RG, et al. 1992. Insulin treatment, endogenous insulin concentration, and ECG abnormalities in diabetic Pima Indians. Cross-sectional and prospective analyses. Diabetes, 41:1141-50.

Macfarlane DP, Paterson KR, Fisher M. 2007. Oral antidiabetic agents as cardiovascular drugs. Diabetes Obes Metab, 9:23-30.

Mak KH, Moliterno DJ, Granger CB, et al. 1997. Influence of diabetes mellitus on clinical outcome in the thrombolytic era of acute myocardial infarction. GUSTO-I Investigators. Global Utilization of Streptokinase and Tissue Plasminogen Activator for Occluded Coronary Arteries. $J$ Am Coll Cardiol, 30:171-9.

Malmberg K. 1997. Prospective randomised study of intensive insulin treatment on long term survival after acute myocardial infarction in patients with diabetes mellitus. DIGAMI (Diabetes Mellitus, Insulin Glucose Infusion in Acute Myocardial Infarction) Study Group. BMJ, 314:1512-5.

Malmberg K, Ryden L, Efendic S, et al. 1995. Randomized trial of insulinglucose infusion followed by subcutaneous insulin treatment in diabetic patients with acute myocardial infarction (DIGAMI study): effects on mortality at 1 year. $J$ Am Coll Cardiol, 26:57-65.

Malmberg K, Ryden L, Wedel H, et al. 2005. Intense metabolic control by means of insulin in patients with diabetes mellitus and acute myocardial infarction (DIGAMI 2): effects on mortality and morbidity. Eur Heart $J, 26: 650-61$. 
Malone JK, Kerr LF, Campaigne BN, et al; Lispro Mixture-Glargine Study Group. 2004. Combined therapy with insulin lispro Mix 75/25 plus metformin or insulin glargine plus metformin: a 16-week, randomized, open-label, crossover study in patients with type 2 diabetes beginning insulin therapy. Clin Ther, 26:2034-44.

Malone JK, Bai S, Campaigne BN, et al. 2005. Twice-daily pre-mixed insulin rather than basal insulin therapy alone results in better overall glycemic control in patients with Type 2 diabetes. Diabet Med, 22:374-81.

Manson JE, Nathan DM, Krolewski AS, et al. 1992. A prospective study of exercise and incidence of diabetes among US male physicians. JAMA, 268:63-7.

Massi-Benedetti M, Federici MO. 1999. Cardiovascular risk factors in type 2 diabetes: the role of hyperglycemia. Exp Clin Endocrinol Diabetes, 107:S120-3.

Mather KJ, Verma S, Anderson TJ. 2001. Improved endothelial function with metformin in type 2 diabetes mellitus. $J$ Am Coll Cardiol, 37:1344-50.

Medici F, Hawa M, Ianari A, et al. 1999. Concordance rate for type II diabetes mellitus in monozygotic twins: actuarial analysis. Diabetologia, 42:146-50.

Meece J. Pharmacoeconomic advantages of insulin analogs. US Pharm. 2006; 31:HS42-50. Available at: http://www.uspharmacist.com/index asp?show=article\&page=8_1920.htm Accessed 30 October 2007.

Meigs JB, Mittleman MA, Nathan DM, et al. 2000. Hyperinsulinemia, hyperglycemia, and impaired hemostasis: The Framingham Offspring Study. JAMA, 283:221-8.

Meneghini LF, Rosenberg KH, Koenen C, et al. 2007. Insulin detemir improves glycemic control with less hypoglycaemia and no weight gain in patients with type 2 diabetes who were insulin naive or treated with NPH or insulin glargine: clinical practice experience from a German subgroup of the PREDICTIVE study. Diabetes Obes Metab, 9:418-27.

Monnier L, Lapinski H, Colette C. 2003. Contributions of fasting and postprandial plasma glucose increments to the overall diurnal hyperglycemia of type 2 diabetic patients. Diabetes Care, 26:881-5.

Monnier L, Colette C, Dunseath GJ, et al. 2007. The loss of postprandial glycemic control precedes stepwise deterioration of fasting with worsening diabetes. Diabetes Care, 30:263-9.

Muis MJ, Bots ML, Grobbee DE, et al. 2005. Insulin treatment and cardiovascular disease; friend or foe? A point of view. Diabet Med, 22:118-26.

Nathan DM, Lachin J, Cleary P, et al. 2003. Diabetes Control and Complications Trial/Epidemiology of Diabetes Interventions and Complications Study Research Group. Intensive diabetes therapy and carotid intima-media thickness in type 1 diabetes mellitus. N Engl J Med, 348:2294-303.

Nathan DM, Cleary PA, Backlund JY, et al. 2005. Diabetes Control and Complications Trial/Epidemiology of Diabetes Interventions and Complications Study Research Group. Intensive diabetes treatment and cardiovascular disease in patients with type 1 diabetes. $N$ Engl $J$ Med, 353:2643-53.

Nathan DM, Buse JB, Davidson MB, et al. 2006. Management of hyperglycemia in type 2 diabetes: a consensus algorithm for the initiation and adjustment of therapy. A consensus statement from the American Diabetes Association and the European Association for the Study of Diabetes. Diabetologia, 49:1711-21.

Nissen SE, Wolski K. 2007. Effect of rosiglitazone on the risk of myocardial infarction and death from cardiovascular causes. $N$ Engl $J$ Med, 356:2457-71.

O'Keefe JH Jr, Miles JM, Harris WH, et al. 1999. Improving the adverse cardiovascular prognosis of type 2 diabetes. Mayo Clin Proc, 74:171-80.

Philis-Tsimikas A, Charpentier G, Clauson P, et al. 2006. Comparison of oncedaily insulin detemir with NPH insulin added to a regimen of oral antidiabetic drugs in poorly controlled type 2 diabetes. Clin Ther, 28:1569-81.

Polonsky KS, Given BD, Hirsch LJ, et al. 1988. Abnormal patterns of insulin secretion in non-insulin-dependent diabetes mellitus. $N$ Engl JMed, 318:1231-9.
Poulsen P, Kyvik KO, Vaag A, et al. 1999. Heritability of type II (noninsulin-dependent) diabetes mellitus and abnormal glucose tolerance - a population-based twin study. Diabetologia, 42:139-45.

Raskin P, Allen E, Hollander P, et al. 2005. Initiating Insulin Therapy in Type 2 Diabetes: a comparison of biphasic and basal insulin analogs. Diabetes Care, 28:260-5.

Reaven GM. 1995. Pathophysiology of insulin resistance in human disease. Physiol Rev, 75:473-86.

Ridderstraale M, Gudbjoernsdottir S, Eliasson B, et al. 2006. Obesity and cardiovascular risk factors in type 2 diabetes: results from the Swedish National Diabetes Register. J Intern Med, 259:314-22.

Riddle MC, Rosenstock J, Gerich J. Insulin Glargine 4002 Study Investigators. 2003. The Treat-to-Target Trial: Randomized addition of glargine or human NPH insulin to oral therapy of type 2 diabetic patients. Diabetes Care, 26:3080-6.

Ridker PM, Hennekens CH, Buring JE, et al. 2000. C-reactive protein and other markers of inflammation in the prediction of cardiovascular disease in women. $N$ Engl J Med, 342:836-43.

Rius Riu F, Salinas Vert I, Lucas Martín A, et al. 2003. A prospective study of cardiovascular disease in patients with Type 2 diabetes. 6.3 years of follow-up. J Diabetes Complications, 17:235-42.

Roach P, Yue L, Arora V. Humalog Mix 25 Study Group. 1999. Improved postprandial glycemic control during treatment with Humalog Mix25, a novel protamine-based insulin lispro formulation. Diabetes Care, 22:1258-61.

Schalkwijk CG, Poland DC, van Dijk W, et al. 1999. Plasma concentration of C-reactive protein is increased in type I diabetic patients without clinical macroangiopathy and correlates with markers of endothelial dysfunction: evidence for chronic inflammation. Diabetologia, 42:351-7.

Schernthaner G. 1996. Cardiovascular mortality and morbidity in type-2 diabetes mellitus. Diabetes Res Clin Pract, 31:S3-13.

Schramm TK, Gislason G, Rasmussen S, et al. 2007. Cardiovascular morbidity and mortality in diabetes patients receiving glucose reducing treatment: a population-based study of 3.3 million. American Diabetes Association 2007 Scientific Sessions; Chicago, IL. Poster 692.

Stamler J, Vaccaro O, Neaton JD, et al. 1993. Diabetes, other risk factors, and 12-yr cardiovascular mortality for men screened in the Multiple Risk Factor Intervention Trial. Diabetes Care, 16:434-44.

St. John Sutton M, Rendell M, Dandona P, et al. 2002. A comparison of the effects of rosiglitazone and glyburide on cardiovascular function and glycemic control in patients with type 2 diabetes. Diabetes Care, 25:2058-64.

Stolar MW, Chilton RJ. 2003. Type 2 diabetes, cardiovascular risk, and the link to insulin resistance. Clin Ther, 25:B4-31.

Stratton IM, Adler AI, Neil AW, et al. 2000. Association of glycaemia with macrovascular and microvascular complications of type 2 diabetes (UKPDS 35): prospective observational study. BMJ, 32:405-12.

Turner R, Cull C, Holman R, for the UK Prospective Diabetes Study Group. 1996. UKPDS 17: a 9-year update of a randomized, controlled trial on the effect of improved metabolic control on complications in noninsulin-dependent diabetes mellitus. Ann Intern Med, 124:136-45.

Turner RC, Holman RR, Stratton IM, et al. 1998. Effect of intensive bloodglucose control with metformin on complications in overweight patients with type 2 diabetes (UKPDS 34). Lancet, 352:854-65.

Turner RC, Cull CA, Frighi V, et al. 1999. Glycemic control with diet, sulfonylurea, metformin, or insulin in patients with type 2 diabetes mellitus: progressive requirements for multiple therapies. JAMA, 281:2005-12.

UK Prospective Diabetes Study Group. 1998. Intensive blood-glucose control with sulphonylureas or insulin compared with conventional treatment and risk of complications in patients with type 2 diabetes (UKPDS 33). Lancet, 352:837-53.

UK Prospective Diabetes Study Group. 1998. Tight blood pressure control and risk of macrovascular and microvascular complications in type 2 diabetes (UKPDS 38). BMJ, 317:703-13.

Van de Laar FA, Lucassen PLBJ: No evidence for a reduction of myocardial infarctions by acarbose (Letter). Eur Heart J 25: 1179, 2004.

Van De Laar FA, Lucassen PL, Akkermans RP, et al. 2005. A-Glucosidase inhibitors for patients with type 2 diabetes: results from a Cochrane systematic review and meta-analysis. Diabetes Care, 28:154-63. 
Vilsbøll T, Zdravkovic M, Le-Thi T, et al. 2006. Liraglutide significantly improves glycemic control, and lowers body weight without risk of either major or minor hypoglycemic episodes in subjects with type 2 diabetes. Diabetes, 55:A27.

Watanabe Y, Sunayama S, Shimada K, et al. 2000. Troglitazone improves endothelial dysfunction in patients with insulin resistance. J Atheroscler Thromb, 7:159-63.

Wing R. 1995. Use of very-low-calorie diets in the treatment of obese persons with non-insulin-dependent diabetes mellitus. J Am Diet Assoc, 95:569-74.

Wolf AM, Colditz GA. 1998. Current estimates of the economic cost of obesity in the United States. Obes Res, 6:97-106.
Wright A, Felix Burden AC, Paisey RB, et al. 2002. Sulfonylurea inadequacy. Efficacy of addition of insulin over 6 years in patients with type 2 diabetes in the UK Prospective Diabetes Study (UKPDS 57). Diabetes Care, 25:330-6.

Wulffele MG, Kooy A, Zeeuw D, et al. 2004. The effect of metformin on blood pressure, plasma cholesterol and triglycerides in type 2 diabetes mellitus: a systematic review. J Intern Med, 256:1-14.

Yki-Jarvinen H, Dressler A, Ziemen M. HOE 901/3002 Study Group. 2000. Less nocturnal hypoglycaemia and better post-dinner glucose control with bedtime insulin glargine compared with bedtime NPH insulin during insulin combination therapy in type 2 diabetes. Diabetes Care, 23: $1130-6$ 